08

\title{
Улучшения качества лазерного скрайбирования прозрачного проводящего оксида при изготовлении тонкопленочного солнечного модуля
}

\author{
(C) Ф.С. Егоров, ${ }^{1,2}$ А.В Кукин, ${ }^{3}$ Е.И. Теруков, ${ }^{3,4}$ А.С. Титов ${ }^{3,4,}$ \\ ${ }^{1} \mathrm{OOO} \mathrm{„Хевел“,}$ \\ 429952 Новочебоксарск, Россия \\ 2 Чувашский государственный университет им. И.Н. Ульянова, \\ 428000 Чебоксары, Россия \\ ${ }^{3}$ ООО „Научно-технический центр тонкопленочных технологий в энергетике“, \\ 194064 Санкт-Петербург, Россия \\ ${ }^{4}$ Физико-технический институт им. А.Ф. Иоффре РАН, \\ 194021 Санкт-Петербург, Россия \\ ฯe-mail: titovoz@gmail.com
}

(Поступило в Редакцию 22 мая 2017 г.)

Неоднородность толщины фронтального прозрачного проводящего оксида (ППО) при изготовлении тонкопленочного солнечного модуля (ТПСМ) на основе микроморфной технологии влияет на качество лазерного скрайбирования P1 (P1 - скрайбирование во фронтальном слое ППО). Предложен метод улучшения неоднородности толщины фронтального ППО путем модификации существующей системы подачи газов вакуумной установки LPCVD (TCO1200) с использованием газораспределительных трубок. Неравномерность осаждения по толщине снижена с 15.2 до $11.4 \%$, что улучшило неравномерности по сопротивлению фронтального ППО и светорассеивающего фактора ТПСМ. Помимо этого, в 7 раз уменьшилось количество лазерных скрайбов Р1 с недопустимым значением сопротивления изоляции (менее $2 \mathrm{M} \Omega$ ), снизилось количество объемов расплавов по краям скрайба Р1, что привело к увеличению шунтирующего сопротивления ТПСМ на $56 \Omega$. Улучшение параметров фронтального ППО с применением метода газораспределительных труб увеличило выходную мощность ТПСМ на $0.4 \mathrm{~W}$.

DOI: 10.21883/JTF.2018.04.45726.2346

\section{Введение}

В производстве тонкопленочных солнечных модулей (ТПСМ) на основе аморфного и микрокристаллического кремния для снижения электрических потерь проводится сегментация ячеек и их последовательное соединение [1]. Данный процесс проводится в три этапа лазерного скрайбирования: P1, P2 и Р3, качество которых влияет на выходные характеристики ТПСМ [2]. Первый этап лазерного скрайбирования P1 необходим для разделения фронтального прозрачного проводящего оксида (ППО) в соседних ячейках ТПСМ. Скрайб Р1 имеет два вида потерь - это электрические [2] и оптические [3]. Электрические потери обусловлены сопротивлением изоляции $R_{\text {is }}$ скрайба Р1 и его влиянием на шунтирующее сопротивление $R_{\text {sh }}$ ТПСМ, а оптические потери связаны с площадью, занимаемой скрайбом Р1. В данном случае решалась проблема уменьшения потерь на скрайбах Р1 путем улучшения неоднородности толщины фронтального ППО при помощи модификации существующей системы подачи газов вакуумной установки LPCVD (ТCO1200) с использованием газораспределительные трубок.

\section{Методика эксперимента}

Скрайб P1 влияет на эффективность ТПСМ через следующие электрические свойства: сопротивление изоляции $R_{\text {is }}$; шунтирование структуры $a-\mathrm{Si}: \mathrm{H} / \mu c-\mathrm{Si}: \mathrm{H}$ $\left(R_{\mathrm{sh}}\right.$ - шунтирующее сопротивление ТПСМ).

При лазерном скрайбировании с облучением со стороны стекла удаление пленки проводится при помощи двух различных механизмов: микровзрыва или теплового расширения [4]. Микровзрыв - это процесс, при котором пленка облучается лазерным импульсом с энергией, достаточной для испарения поверхностного слоя (со стороны стекла), до состояния плазмы. Это приводит к созданию избыточного давления и возникновению волнового удара. Волновой удар инициирует увеличение избыточного давления в 5 раз [5] вследствие ограничивающего фактора. Ограничивающим фактором в данном случае является та часть пленки, которая не подвергалась фазовому переходу.

В случае, когда энергия лазерного импульса недостаточна для плавления пленки, т.е. в местах, где толщина фронтального ППО больше критического значения, удаление происходит при помощи механизма теплового расширения. При этом удаление пленки механизмом теплового расширения происходит за время $\sim 5 \mu \mathrm{s}$, а 
$a$

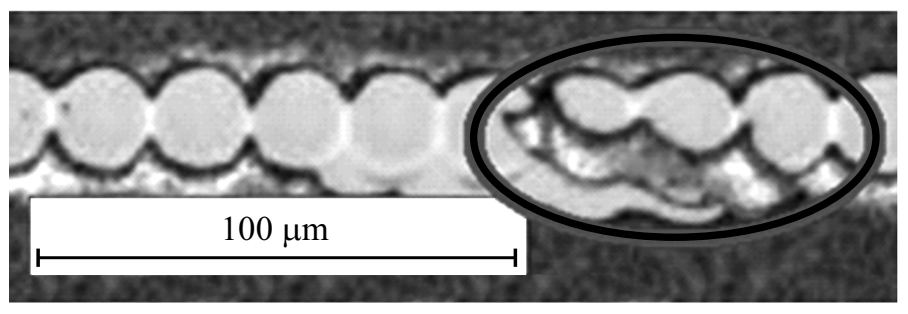

$b$

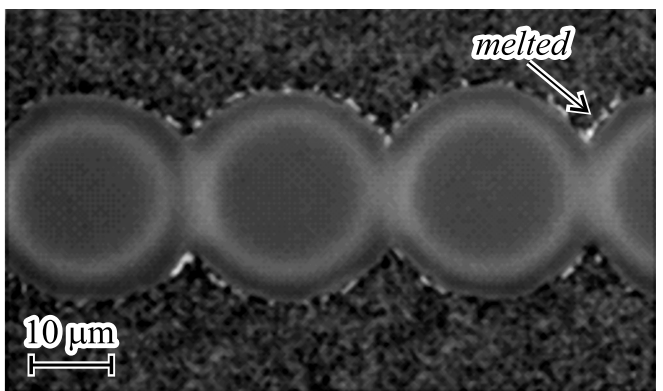

Рис. 1. $a$ - шунтирующий элемент при $h>1.9 \mu \mathrm{m} ; b-$ расплав при $h<1.4 \mu \mathrm{m}$.

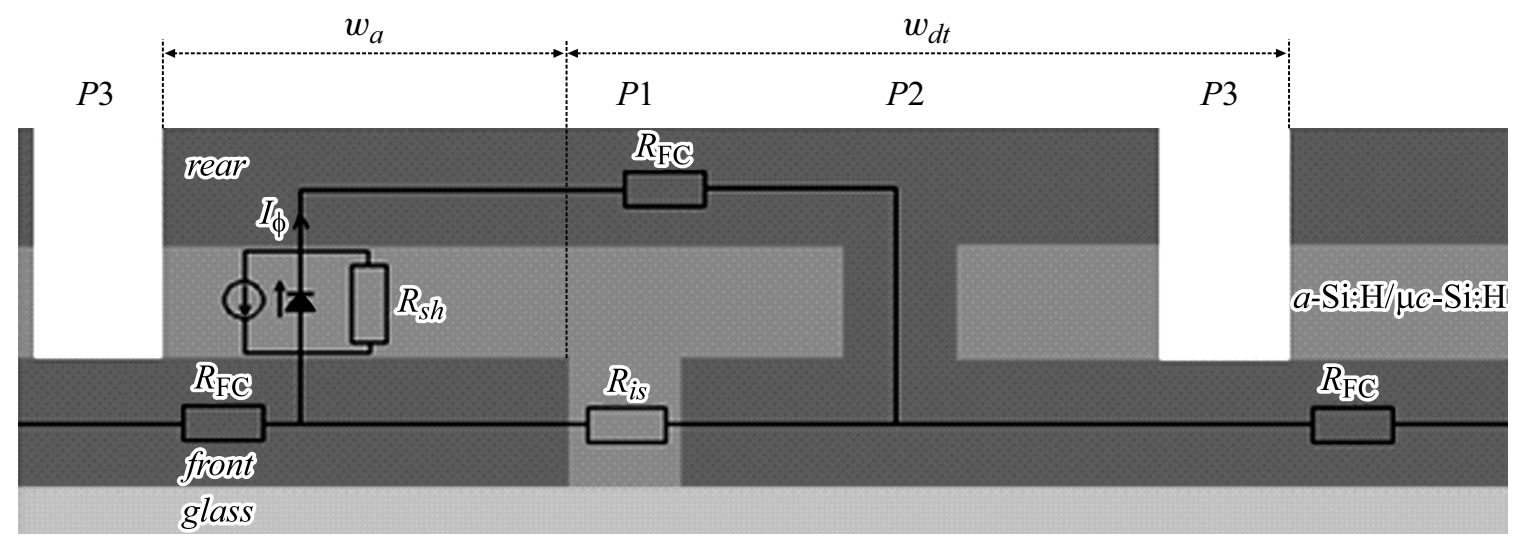

Рис. 2. Схематическое изображение сопротивлений в структуре ТПСМ $\left(w_{\mathrm{a}}-\right.$ активная площадь ячейки, $w_{\mathrm{dt}}-$ мертвая зона ячейки, $R_{\mathrm{FC}}$ и $R_{\mathrm{BC}}-$ сопротивление фронтального и тыльного ППО соответственно), области front и rear - ППО область. $a-\mathrm{SiiH} j \mu-\mathrm{SiH}$ - генерирующие слои.

микровзрывом менее $25 \mathrm{~ns}$ [4]. В следствие преобладания механизма теплового расширения перед микровзрывом возникают нарушения изоляции (шунты) $R_{\text {is }}$ скрайба $\mathrm{P} 1$ (рис. 1,a).

На рис. 1, а показан шунт скрайба Р1, возникший изза отколотого элемента (скола) с фронтального ППО. Здесь нарушение $R_{\text {is }}$ скрайба P1 вызвано тем, что толщина $h$ фронтального ППО составила более $1.9 \mu \mathrm{m}$. Причину возникновения отколотого элемента на месте фронтального ППО, где его толщина $h$ более $1.9 \mu \mathrm{m}$, можно объяснить из следующих соображений. Существует формула для расчета температуры пленки под воздействием лазерного излучения:

$$
T=\frac{q_{0} A t}{\rho c h}
$$

где $T$ - температура, $q_{0}$ - мощность импульса, $h-$ толщина ППО, $A$ - поглощательная способность ППО, $t$ - длительность лазерного импульса, $\rho$ - плотность ППО, $c$ - теплоемкость.

Таким образом, можно сделать вывод, что пленка не нагрелась по толщине до требуемых значений для микровзрыва [1], а именно - до температуры испарения пленки [4].
C другой стороны, если толщины пленки менее $1.4 \mu \mathrm{m}$, по краям скрайбов образуются расплавы (рис. $1, b)$. Эти расплавы становятся причиной шунтирования структуры $a-\mathrm{Si}: \mathrm{H} / \mu c-\mathrm{Si}: \mathrm{H}$, а также уменьшают шунтирующее сопротивление $R_{\mathrm{sh}}$ в ТПСМ [6]. На локальных участках с расплавами фронтального ППО структура $a-\mathrm{Si}: \mathrm{H} / \mu c-\mathrm{Si}: \mathrm{H}$ подвержена механическим напряженностям. Данные напряженности частично снимаются образованием дефектов в структуре $a-\mathrm{Si}: \mathrm{H} / \mu c-\mathrm{Si}: \mathrm{H}[1]$, что ведет к уменьшению значения $R_{\mathrm{sh}}$ в ТПСМ.

Сопротивление изоляции $R_{\text {is }}$ скрайба P1 после процесса скрайбирования фронтального ППО должно быть больше $2 \mathrm{M} \Omega$ [3]. После формирования слоев оно зависит от качества скрайба и удельного сопротивления структуры $a$-Si : H/ $\mu c-\mathrm{Si}: \mathrm{H}$ (рис. 2). Значение удельного сопротивления $a-\mathrm{Si}: \mathrm{H} / \mu c-\mathrm{Si}: \mathrm{H}$ практически постоянно по всей площади ТПСМ, поэтому $R_{\text {is }}$ определяется только качеством лазерного скрайбирования Р1. Фронтальный ППО с толщиной более $1.9 \mu \mathrm{m}$ в местах лазерного скрайбирования $\mathrm{P} 1$ может привести к падению $R_{\text {is }}$ до нуля, что фактически означает соединение фронтальных ППО у двух соседних ячеек (рис. 2). Это приводит к 


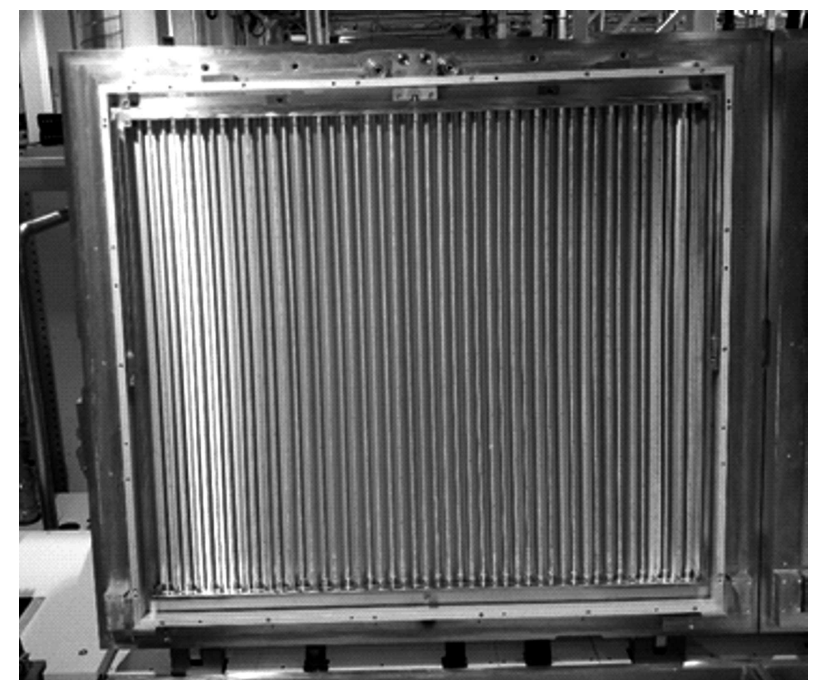

Рис. 3. Газораспределительные трубки в системе подачи газов установки ТСО1200.

уменьшению напряжения холостого хода $U_{\text {ос }}$ на $\mathrm{BAX}$ ТПСМ [7].

Целью настоящей работы является улучшение характеристик каждого скрайба Р1 для достижения сопротивления изоляции $R_{\text {is }}$ более $2 \mathrm{M} \Omega$ и снижения объемов расплавов фронтального ППО на скрайбах. Для достижения поставленной цели необходимо решить задачу по уменьшению неравномерности толщины $h$ фронтального ППО, которая должна находиться в пределах значений от $1.4 \mu \mathrm{m}$ до $1.9 \mu \mathrm{m}$.

Для уменьшения неравномерности толщины фронтального ППО была создана модификация существующей системы подачи газов вакуумной установки LPCVD (ТCO1200) с использованием газораспределительных трубок (рис. 3). В трубках проделаны специальные отверстия в количестве 29 штук диаметром $2 \mathrm{~mm}$, расположенные друг от друга на расстоянии $40 \mathrm{~mm}$, длина трубки - $1203 \mathrm{~mm}$, диаметр боковых отверстий $10 \mathrm{~mm}$.

При осаждении фронтального ППО (оксида цинка легированного бором $-\mathrm{ZnO}: \mathrm{B})$, используются следующие параметры установки ТСО1200:

- давление в процессной камере $5.15 \pm 0.03 \mathrm{mbar} ;$

- потоки газов: а) диэтилцинк $2690 \pm 3 \mathrm{sccm}$ ( $\mathrm{sccm}$ стандартный кубический сантиметр в минуту), б) диборан $250 \pm 1 \mathrm{sccm}, \quad$ в) вода $3273 \pm 4 \mathrm{sccm}$, г) водород $400 \pm 1 \mathrm{sccm}$.

В процессе лазерного скрайбирования фронтального ППО используются следующие параметры лазера: мощность лазерного луча $q_{0}=300 \mathrm{~mW}$, гауссовское распределение интенсивности по сечению луча, частота следований лазерных импульсов $f=50 \mathrm{kHz}$, скорость сканирования $v=72000 \mathrm{~mm} / \mathrm{m}$; расстояние между двумя центрами отверстий в скрайбе Р1 $30 \mu \mathrm{m}$; длительность лазерного импульса $t=30 \mathrm{~ns}$.

\section{Экспериментальные результаты}

В эксперименте проводилось осаждение фронтального ППО с использованием газораспределительных трубок и без них. Изготовленные подложки подверглись лазерному скрайбированию Р1 и анализу.

В табл. 1 показано распределение неравномерности толщины фронтального ППО, осажденного с применением газораспределительных труб и без них. Видно, что толщина фронтального ППО меняется от $1.36 \mu \mathrm{m}$ до $2.05 \mu \mathrm{m}$. Далее фронтальный ППО подвергался к процессу лазерного скрайбирования Р1. Затем проводились измерения сопротивления изоляции $R_{\text {is }}$ и визуальный осмотр оптическим микроскопом каждого скрайба P1. В ходе исследования были обнаружены расплавы по краям скрайбам Р1 в координате $x=17 \mathrm{~mm}, y=17 \mathrm{~mm}$ в табл. 1 . Измерения $R_{\text {is }}$ показаны на рис. 4 . Нарушение $R_{\text {is }}$ скрайба Р1 в основном наблюдается в области, где $h>1.9 \mu \mathrm{m}$, из них в 4 скрайбах Р1 $R_{\text {is }}=0$. Шунтирующее сопротивление данного ТПСМ $R_{\mathrm{sh}}=211 \Omega$.

В табл. 2 показано распределение толщины фронтального ППО, осажденного с применением газораспределительных трубок. Видно, что $h$ меняется от 1.44 до $1.89 \mu \mathrm{m}$, таким образом, неравномерность распределения толщины по площади уменьшилась на 5.7\%.

Таблица 1. Распределение толщины $h \mathrm{~nm}$ фронтального ППО, осажденного без применения газораспределительных трубок. Абсолютная точность измерения $\pm 7 \mathrm{~nm}$

\begin{tabular}{c|c|c|c|c|c|c|c|c}
\hline \multirow{2}{*}{$y, \mu \mathrm{m}$} & \multicolumn{7}{|c}{$x, \mathrm{~mm}$} \\
\cline { 2 - 9 } & 17 & 198 & 379 & 560 & 740 & 921 & 1102 & 1283 \\
\hline 1083 & 1403 & 1698 & 1736 & 1772 & 1813 & 1731 & 1744 & 1566 \\
931 & 1608 & 1633 & 1758 & 1774 & 1753 & 1741 & 1727 & 1787 \\
778 & 1942 & 1882 & 1913 & 1957 & 1959 & 1943 & 1901 & 2050 \\
626 & 1960 & 1816 & 1925 & 1925 & 1947 & 1928 & 1870 & 2026 \\
474 & 1969 & 1839 & 1930 & 1944 & 1959 & 1942 & 1903 & 2029 \\
322 & 1951 & 1851 & 1925 & 1976 & 1954 & 1926 & 1869 & 2017 \\
169 & 1673 & 1709 & 1841 & 1875 & 1846 & 1814 & 1748 & 1774 \\
17 & 1358 & 1538 & 1611 & 1737 & 1738 & 1600 & 1693 & 1430
\end{tabular}

Таблица 2. Распределение толщины $h \mathrm{~nm}$ фронтального ППО, осажденного с применением газораспределительных трубок

\begin{tabular}{c|c|c|c|c|c|c|c|c}
\hline \multirow{2}{*}{$y, \mu \mathrm{m}$} & \multicolumn{7}{|c}{$x, \mathrm{~mm}$} \\
\cline { 2 - 9 } & 17 & 198 & 379 & 560 & 740 & 921 & 1102 & 1283 \\
\hline 1083 & 1411 & 1662 & 1605 & 1661 & 1730 & 1696 & 1689 & 1433 \\
931 & 1662 & 1687 & 1742 & 1742 & 1772 & 1795 & 1743 & 1694 \\
778 & 1800 & 1773 & 1804 & 1817 & 1866 & 1878 & 1817 & 1858 \\
626 & 1818 & 1729 & 1787 & 1794 & 1806 & 1839 & 1770 & 1865 \\
474 & 1874 & 1769 & 1797 & 1789 & 1812 & 1834 & 1765 & 1872 \\
322 & 1892 & 1781 & 1817 & 1813 & 1831 & 1842 & 1794 & 1888 \\
169 & 1770 & 1751 & 1787 & 1792 & 1788 & 1784 & 1766 & 1811 \\
17 & 1443 & 1688 & 1640 & 1826 & 1729 & 1610 & 1742 & 1504
\end{tabular}




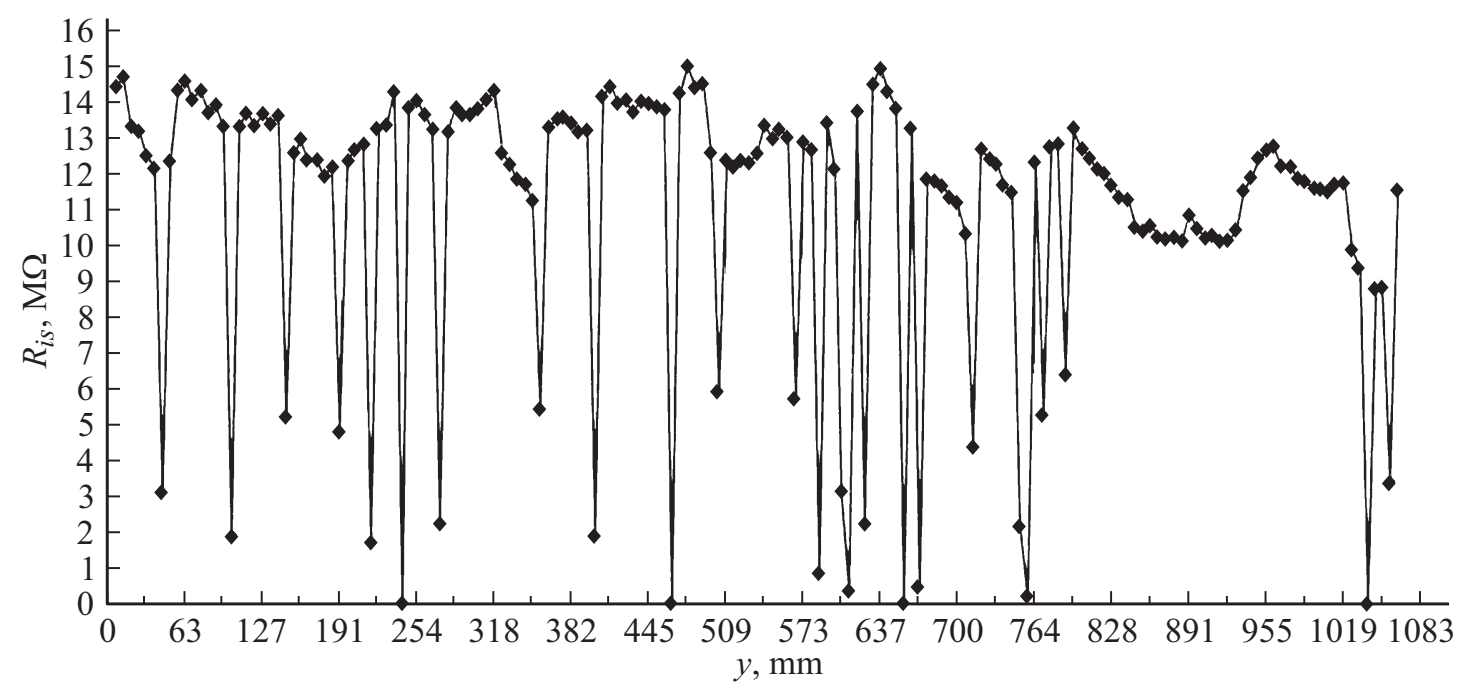

Рис. 4. Результаты измерения сопротивления изоляции после скрайбирования фронтального ППО. Точность измерения $1 k \Omega< \pm 0.02 \%<10 \mathrm{M} \Omega$ и $10 \mathrm{M} \Omega< \pm 0.41 \%<100 \mathrm{M} \Omega$.

Таблица 3. Распределение Наzе-фактора [\%]: $a-$ без применения газораспределительных трубок, $b-\mathrm{c}$ применением газораспределительных трубок. Для измерения параметра Haze используется монохроматическое излучение с длиной волны $600 \mathrm{~nm}$. Относительная точность измерения $\pm 0.1 \%$

\begin{tabular}{|c|c|c|c|c|c|}
\hline \multirow{2}{*}{$y, \mu \mathrm{m}$} & \multicolumn{5}{|c|}{$x, \mathrm{~mm}$} \\
\hline & 75 & 363 & 650 & 938 & 1225 \\
\hline 1025 & 21.0 & 31.9 & 27.1 & 30.7 & 21.0 \\
\hline 788 & 24.1 & 34.2 & 37.5 & 36.4 & 26.6 \\
\hline 550 & 20.6 & 23.2 & 29.4 & 27.8 & 21.4 \\
\hline 313 & 19.8 & 27.5 & 36.2 & 34.2 & 26.9 \\
\hline 75 & 15.5 & 31.1 & 34.8 & 30.0 & 24.3 \\
\hline
\end{tabular}

\begin{tabular}{cc|c|c|c|c|c}
\hline \multirow{2}{*}{\multicolumn{2}{c}{$y, \mu \mathrm{m}$}} & \multicolumn{5}{|c}{$x, \mathrm{~mm}$} \\
\cline { 2 - 6 }$b$ & 75 & 363 & 650 & 938 & 1225 \\
\hline & 1025 & 27.1 & 27.8 & 27.1 & 29.8 & 27.5 \\
& 788 & 25.8 & 29.2 & 30.8 & 30.9 & 29.8 \\
& 550 & 24.3 & 27.3 & 28.7 & 28.5 & 28.0 \\
313 & 23.1 & 29.3 & 30.9 & 29.6 & 28.6 \\
& 75 & 26.4 & 28.7 & 28.8 & 27.0 & 27.8
\end{tabular}

Далее данный образец подвергся процессу лазерного скрайбирования, а затем было измерено сопротивление изоляции каждой ячейки $R_{\text {is }}$ (рис. 5). Видно, что отсутствуют скрайбы Р1 с значением сопротивления изоляции $R_{\text {is }}$ менее $2 \mathrm{M} \Omega$.

При визуальном осмотре скрайбов Р1 не обнаружено наличие расплавов в изготовленном данном ТПСМ, что объясняется достаточно высоким значением шунтирующего сопротивления $R_{\mathrm{sh}}=378 \Omega$.

Применение газораспределительных трубок для осаждения фронтального ППО не только улучшает сопротивления изоляции скрайбов, но и положительно влияет на неравномерность распределения светорассеивающего фактора $(\mathrm{Haze})$ и сопротивления $\left(R_{\mathrm{FC}}\right)$. Улучшение данных параметров увеличивает стабильность согласованности по фототоку ячеек, соединенных последовательнопараллельно, что, в свою очередь увеличивает эффективность ТПСМ [6,7]. В табл. 3 показано распределение Haze-фактора. Без применения газораспреде-

Таблица 4. Распределение $R_{\mathrm{FC}}\left[\Omega / \mathrm{m}^{2}\right]$ фронтального ППО: $a$ - без применения газораспределительных трубок, $b-$ с применением газораспределительных труб. Относительная точность измерения $\pm 1 \%$

\begin{tabular}{cc|c|c|c|c|c|c|c|c}
\hline & \multicolumn{8}{|c}{$x, \mathrm{~mm}$} \\
\cline { 2 - 9 }$a$ & \multicolumn{1}{c|}{$y, \mu \mathrm{m}$} & 17 & 198 & 379 & 560 & 740 & 921 & 1102 & 1283 \\
\hline 1083 & 40.34 & 31.01 & 28.92 & 27.74 & 27.38 & 29.74 & 29.10 & 30.10 \\
931 & 30.55 & 29.01 & 26.29 & 26.29 & 27.02 & 27.29 & 27.02 & 24.48 \\
& 21.40 & 19.32 & 19.68 & 21.31 & 20.22 & 20.13 & 19.41 & 19.77 \\
626 & 21.58 & 19.41 & 17.33 & 18.05 & 18.23 & 17.96 & 18.41 & 20.50 \\
474 & 21.31 & 18.50 & 17.33 & 17.42 & 17.42 & 17.51 & 17.60 & 20.41 \\
322 & 21.22 & 19.23 & 18.23 & 18.32 & 19.4 & 19.86 & 19.32 & 20.95 \\
169 & 25.75 & 25.84 & 23.76 & 22.67 & 23.40 & 24.75 & 25.66 & 2.48 \\
17 & 43.69 & 35.17 & 31.64 & 27.65 & 28.56 & 32.64 & 32.91 & 41.61
\end{tabular}

\begin{tabular}{|c|c|c|c|c|c|c|c|c|}
\hline \multirow[b]{2}{*}{$y, \mu \mathrm{m}$} & \multicolumn{8}{|c|}{$x, \mathrm{~mm}$} \\
\hline & 17 & 198 & 379 & 560 & 740 & 921 & 1102 & 1283 \\
\hline 1083 & 35.72 & 26.20 & 28.29 & 26.11 & 24.57 & 25.21 & 26.02 & 35.81 \\
\hline 931 & 25.57 & 22.13 & 22.13 & 22.31 & 21.67 & 21.13 & 21.95 & 25.75 \\
\hline 778 & 20.77 & 17.96 & 18.50 & 19.14 & 18.96 & 18.32 & 18.41 & 21.22 \\
\hline 626 & 20.68 & 17.87 & 17.69 & 18.87 & 19.05 & 18.32 & 18.59 & 20.68 \\
\hline 474 & 20.22 & 17.51 & 18.50 & 18.96 & 18.87 & 18.23 & 18.77 & 20.59 \\
\hline 322 & 18.96 & 17.42 & 18.23 & 18.87 & 18.87 & 18.59 & 18.23 & 19.68 \\
\hline 169 & 21.04 & 19.69 & 19.86 & 20.22 & 20.41 & 20.59 & 20.04 & 21.40 \\
\hline 17 & 33.18 & 25.57 & 26.39 & 24.30 & 24.03 & 27.02 & 24.48 & 31.64 \\
\hline
\end{tabular}




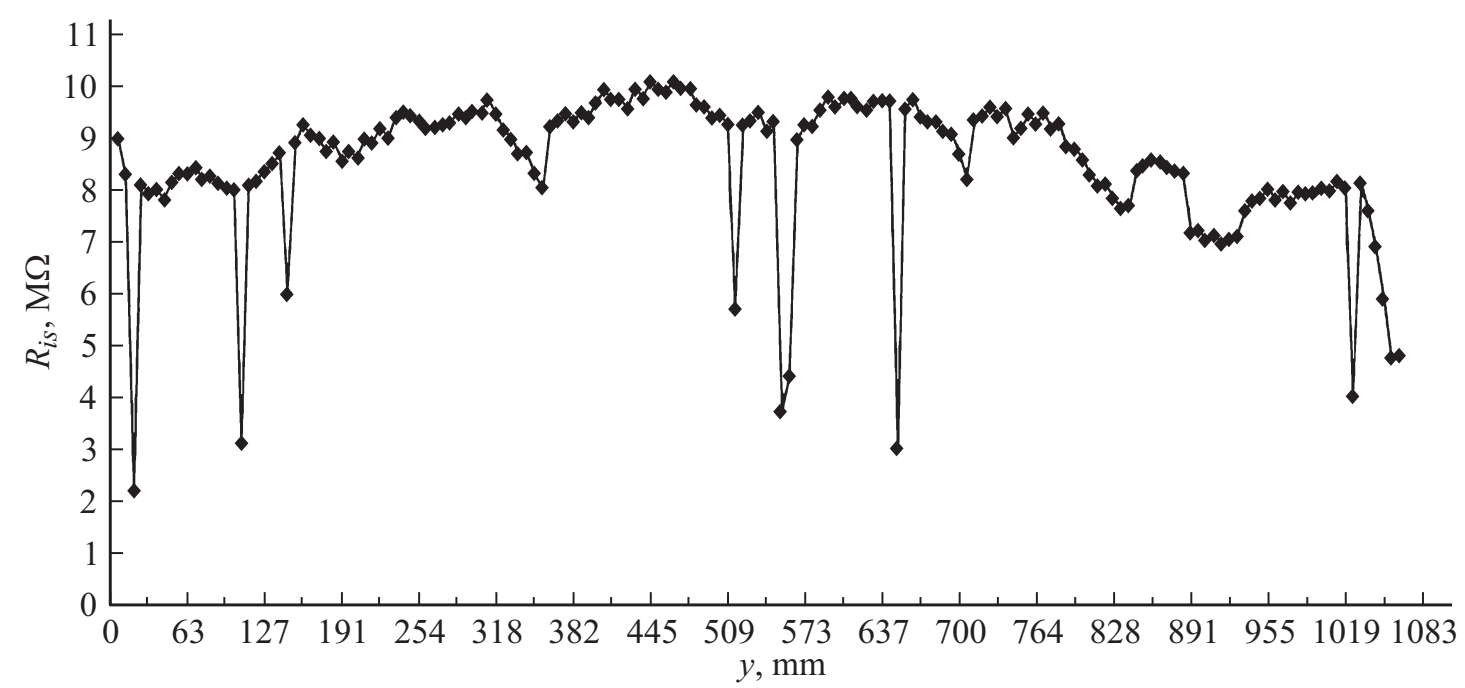

Рис. 5. Результаты измерения сопротивления изоляции после скрайбирования фронтального ППО.

Таблица 5. Сравнение средних параметров

\begin{tabular}{c|c|c|c|c|c|c}
\hline TCO1200 & $\begin{array}{c}R_{\text {is }}, \\
\mathrm{M} \Omega\end{array}$ & $\begin{array}{c}R_{\text {sh }}, \\
\Omega\end{array}$ & $h^{*}, \%$ & Haze,$\%$ & $R_{\mathrm{FC}}^{*} \%$ & $P, \mathrm{~W}$ \\
\hline без труб & 6.8 & 310 & 15.2 & 37 & 51.1 & 136.3 \\
с трубками & 8.5 & 366 & 11.4 & 13.8 & 37.4 & 136.7
\end{tabular}

лительных трубок неравномерность Наzе изменяется от 15.5 до $37.5 \%$ (табл. 3,a). В случае применения газораспределительных труб неравномерность распределения Наzе-фактора уменьшается на $13.3 \%$ (табл.3, $b$ ). Максимальное и минимальное значения Haze-фактора составляет 23.1 и $30.9 \%$ соответственно.

В табл. 4 показано распределение сопротивления $R_{\mathrm{FC}}$ фронтального ППО. Распределение сопротивления $R_{\mathrm{FC}}$, в случае осаждения фронтального ППО без применения газораспределительных трубок изменяется в диапазоне от 17.33 до $43.69 \Omega / \mathrm{m}^{2}$ (табл. 4,a). При применении газораспределительных трубок сопротивление $R_{\mathrm{FC}}$ изменяется лишь от 17.42 до $35.81 \Omega / \mathrm{m}^{2}$ (табл. $4, b$ ).

Для уменьшения случайных погрешностей, связанных с эксплуатацией оборудования ТСО1200, проведены серии испытаний: на одном и том же оборудовании ТСО1200 (на заводе ООО „Хевел“, Новочебоксарск) проведено осаждение фронтального ППО в количестве 6000 штук подложек, с газораспределительными трубками и без них. До начала серии испытаний установка ТСО1200 подвергалось техническому обслуживанию. После технического обслуживания установка (с трубками и без) имеет одинаковые технические условия осаждения ППО. Затем данные подложки подверглись процессу лазерному скрайбированию Р1 вышеуказанными параметрами. Каждая 200-я подложка подверглась измерению следующих параметров: $R_{\text {is }}, R_{\mathrm{sh}}, h$ фронтального ППО, Haze и $R_{\mathrm{FC}}$. В результате данного эксперимента толщина $h$ фронтального ППО находится в диапазоне $1.4<h<1.9 \mu \mathrm{m}$.

В табл. 5 показаны усредненные значения данных параметров. При применении газораспределительных труб среднее значение сопротивления изоляции $R_{\text {is }}$ скрайба P1 выше на $1.7 \mathrm{M} \Omega$. Среднее значение количество скрайбов $\mathrm{P} 1$, имеющих сопротивление изоляции $R_{\text {is }}$ менее $2 \mathrm{M} \Omega$ составляет 1.6 штук. В системе без с труб - это среднее значение в 7 раз больше и составляет 11.2 штук.

Сопротивление изоляции $R_{\text {is }}<2 \mathrm{M} \Omega$ у скрайба P1 в случае применении газораспределительных труб можно объяснить следующим образом: на стекле имеются поверхностные явления в виде коррозийных локальных участков антиотражающего слоя на основе $\mathrm{Fe}_{2} \mathrm{O}_{3}$, различные загрязнения, дефекты и пр. Данные локальные участки влияют на параметр адгезии пленки фронтального ППО к стеклу. В свою очередь, параметр адгезии ППО к стеклу и площадь поверхностных локальных явлений напрямую влияют на качество лазерной обработки пленочных элементов [8]. Соответственно все вышеперечисленное сказывается на сопротивлении изоляции $R_{\text {is }}$ скрайба $\mathrm{P} 1$.

При осаждении фронтального ППО среднее значение шунтирующего сопротивления $R_{\mathrm{sh}}$ ТПСМ увеличилось на $56 \Omega$ (табл. 5). Также существенно улучшились неравномерности распределения по толщине $h^{*}$, светорассеивающему фактору Haze* и сопротивлению $R_{\mathrm{FC}}^{*}$.

В итоге применение газораспределительных труб на установке ТСО1200 стало причиной увеличения выходной мощности $P$ ТПСМ с 136.3 до $136.7 \mathrm{~W}$.

\section{Заключение}

Осаждение фронтального ППО с применением газораспределительных труб улучшило равномерность оса- 
ждения в ТПСМ. Таким образом, цель, поставленная в настоящей работе, достигнута. Уменьшено количество расплавов фронтального ППО. Качество скрайбирования фронтального проводящего оксида возросло в 7 раз (исходя из количества скрайбов Р1 с сопротивлением $R_{\text {is }}>2 \mathrm{M} \Omega$. За счет модификации газовой системы установки LPCVD осаждения снижена неравномерность толщины по площади подложки $1100 \times 1300 \mathrm{~mm}^{2}$, полученные значения толщины слоя при этом укладываются в диапазон 1.4-1.9 $\mu \mathrm{m}$. За счет всего вышеперечисленного удалось повысить сопротивление шунтирующего сопротивления $\left(R_{\mathrm{sh}}\right)$ ТПСМ.

\section{Список литературы}

[1] Heather Booth // JLMN. 2010. Vol. 5. N 3. P. 183-190.

[2] Егоров Ф.С., Охоткин Г.П., Мукина В.А., Редька Д.Н., Кукин А.В. // Вестник Чувашского ун-та. 2015. № 1. С. 5965.

[3] Joar J., Uwe Z., Marika E. // $22^{\text {nd }}$ European Photovoltaic solar Energy Conference. 2007. P. 1922-1925.

[4] Hongliang $W$. et al. // Proc. of NAMRI/SME. 2012. Vol. 40. N 10. P. 361-370.

[5] Zhang W., Yao Y.L. // J. Manufacturing Science and Engineering. 2002. Vol. 124/2. P. 369-378.

[6] Shah Arvin. Thin Film Silicon Solar Cells. Lausanne, EPFL Press, 2010, p. 249.

[7] Chin-Yi Tsai, Chin-Yao Tsai. // J. Nanomaterials. 2014. Vol. ID 86174, P. 10.

[8] Вейко В.П. Лазерная обработка пленочных элементов. Л.: Машиностроение. 1986. 248 с. 